\title{
ACCESS TO A LAWYER IN RURAL AUSTRALIA: THOUGHTS ON THE EVIDENCE We NEED
}

\section{SIMON RICE*}

NSW Law Society membership data 1988-2004 enables mapping over time of the presence and movement of private legal practice in rural NSW. The changing ratio of legal practices per 10000 population is calculated against data from the Australian Bureau of Statistics. In short, while the rural population increases, the number of legal practices decreases at a much slower rate, resulting in an overall drop in the proportion of legal practices in the population. However, although some inferences could be drawn, the data do not go very far in illustrating the nature and degree of, and reasons for, the limits on access to law in rural Australia. One way of thinking about the further research that can be done is to consider the research implications of the many different ways the issue of rural access to law is expressed, and the different dimensions that are emphasised in those formulations.

\section{INTRODUCTION}

The phenomenon of limited access to lawyers in rural Australia is well known, but not well understood.

Research into the full picture of the state of rural legal services in Australia is only recent, following some years after extensive research in the UK to establish there "whether rural inhabitants were disadvantaged in terms of their access to legal services, and, by implication, to justice, compared to people in

\footnotetext{
* The ANU College of Law, Australian National University, Canberra. The research reported in this article was made possible by a grant from Macquarie University when I was a staff member there, and by the NSW Law Society's provision of technical expertise, and membership records until 2004. I am very grateful to Mr Frank Siciliano, an economic geographer in the Department of Environment and Geography at Macquarie University, who analysed and reported the data for me, and to Ms Tiffany Henderson and Mr Patrick Ingle for research assistance at the ANU College of Law.
} 
urban areas'. ${ }^{1}$ It is common to do in Australia as was done in the UK, and hypothesise that '[i]n the face of ample evidence for rural deprivation in respect of other areas of service provision, both public and private ... similar assumptions might reasonably be made about legal services, even though direct evidence of this was very limited' ${ }^{2}$

There is a recent and growing amount of direct evidence relating to legal services in rural Australia. While it generally supports anecdotal and intuitive claims of a problem of limited access to legal services in rural Australia ("the problem'), evidence of the problem is quite thin. In quantitative terms it is limited to measures of numbers of lawyers, and in qualitative terms it recounts a range of views and practices among lawyers and law consumers. While the evidence broadly supports the anecdote and the intuition, it falls well short of describing in detail what is happening in rural Australian legal services, let alone clearly showing the problem.

My own research was intended to provide some of that detail, by mapping the movement over time of lawyers in rural New South Wales (NSW). The widely held view was (and is) that lawyers are moving out of rural Australia, and I wanted to show - almost literally with pins in a series of maps - the extent to which that was the case. I report on that research in the second part of this article. But the experience of that research led me to reflect on how inadequate the pins in the map are as a means of understanding what is happening in rural Australian legal services, and on how much more needs to be known.

As I explain in more detail below, my research shows how many law firms were in different local government areas in NSW from one year to the next. The number of firms in an area can be compared to the area's population, leading to a proportional figure for law firms in population, and it is possible to see, from time to time, which areas 'lost' law firms and which 'gained' them.

It seems unremarkable now to observe that this exercise raises many more questions than it answers. Why did the lawyers move out of (and into) an area? Did they merge their practice, sell it, or walk away from it? How long had they been there? How viable was the practice? Had the economy or demography of the area changed, giving rise to different legal needs? For those who left an area, what expertise and experience did they take with

\footnotetext{
${ }^{1}$ Kim Economides and Mark Blacksell, 'Access to Justice in Rural Britain: Final Report' (1987) 16(4) Anglo-American Law Review 353, 354.

${ }^{2}$ Ibid 354 (emphasis added).
} 
them? Did they leave behind a need for their services or did they leave because there was no longer a need? For those who arrived in an area, what expertise and experience did they bring with them? Had they seen a need for new services, or were they intent on competing? And so on.

I went back to the problem, and saw that it could be - and often is - expressed in different ways, with different emphases, intended or not. Depending on how the problem is expressed, very different questions arise, and research into very different issues is required. The impression I have is that many people are asking questions, and conducting research, according to their own conception of the problem, probably with an idea that they are adding to other efforts directed to the same end. In fact, there is a risk either that the many research efforts are overlapping, with just enough difference in emphasis to obscure the fact, or that they are heading in very different directions that are not complementary or coordinated.

Reading through the growing literature and commentary in Australia about the problem, I saw the many different ways that the problem had been expressed. Setting out examples of what struck me as commonly occurring formulations, I consider what issues are implicit in that particular formulation, and what research they might require. My focus is on the questions that are asked, not on the possible answers that could be given, or that have in fact been given. For some of the questions there is already quite extensive research, and answers have already been proposed; my purpose is to challenge the researchers to be clear about the question - the particular framing of the problem - they are responding to. And for some of the questions there are not yet any answers, nor any relevant research; my purpose in that case is to draw attention to the need for that research.

\section{Framing the IsSUE}

The precise terms of the issue are unclear. I described it above as the problem of limited access to legal services in rural Australia. This finds expression, for example, as a complaint that 'there aren't enough lawyers in the bush'. For those with some experience of rural Australia this may be accepted as a broadly correct observation, but it does not compel a significant and sustained policy response. It requires greater specificity, being clear about, for example, what kind of 'lawyers', what is meant by 'the bush', and how much is 'enough'? 
Before setting out some of the many ways that the issue of access to legal services in rural Australia can be framed ${ }^{3}$ - and some of the resulting implications for the evidence that is needed - I should clarify one issue of terminology. References to 'the bush', 'the country', 'rural Australia', and 'RRR' (regional, rural and remote) are broadly understood, but are not specific; the term 'rural' is elusive, ${ }^{4}$ and 'highly contested'. ${ }^{5}$ And when talking about lawyers, it may make sense to refer to country lawyers, but the term 'bush lawyer' is unfortunately ambiguous. ${ }^{6}$ For consistency, I refer to rural Australia and, for example, to rural towns and rural lawyers. Where, on the map, 'rural' Australia stops and 'city' or 'urban' Australia begins, is a vexed issue which leads to caveats on the data, discussed below.

For purposes of this article, little turns on a precise definition of 'rural'. ${ }^{7}$ It is sufficient for reading the following discussion to think of 'rural' as the bush or the country, as 'non-urban'. In the research reported below, for example, I treat the local government areas of Sydney, Wollongong and Newcastle as urban and the rest of New South Wales as 'rural'. Alston and Kent said when declining to define the terms 'rural' and 'remote' that 'most Australians could

\footnotetext{
${ }^{3}$ That is, 'framed' merely in the sense of 'expressed' or 'stated', and not in the more technical sense of the strategic alternative ways that social movements characterise events and conditions: see David Snow and Robert Benford, 'Ideology, Frame Resonance and Participant Mobilization', in Bert Klandersmans, Hanspeter Kriesi and Sidney G Tarrow (eds), From Structure to Action: Comparing Social Movements Research Across Cultures (JAI Press, 1988) 197, 198.

${ }^{4}$ Skye Saunders and Patricia Easteal, 'Sexual Harassment in Rural Australia: Predicted Nature, Reporting, Employment policies and Legal Response' (Paper to National Rural/Regional Law and Justice Conference, Deakin University School of Law, 19-21 November 2010) 3 n 6, citing E Barclay, J Donnermeyer, J Scott and R Hogg, Crime in Rural Australia (Federation Press, 2007) $3<\mathrm{http}: / / w w w . d e a k i n . e d u . a u /$ buslaw/law/rrjc/papers/saunderseasteal.pdf $>$.

${ }^{5}$ Margaret Alston, 'Globalisation, rural restructuring and health service delivery in Australia: policy failure and the role of social work?' (2007) 15(3) Health and Social Care in the Community 195, 196, citing Alan Black, 'Rural communities and sustainability' in Chris Cocklin and Jacqui Dibden (eds), Sustainability and Change in Rural Australia (UNSW Press, 2005) 20, 20-37.

${ }^{6}$ See, eg, Kevin McDougall and Reid Mortensen 'Bush Lawyers in New South Wales and Queensland: A Spatial Analysis' (2011) 16(1) Deakin Law Review 75, 76 n 3.

${ }^{7}$ Common measures of 'ruralness' have been the Accessibility/Remoteness Index of Australia (ARIA), the Rural Remote Metropolitan Area classification (RRMA), and identifying the 'residual' areas after urban areas are measured according to 'a complex set of rules about population density and size': Graeme Hugo, 'The State of Rural Populations' in Chris Cocklin and Jacqui Dibden (eds), Sustainability and Change In Rural Australia (UNSW Press, 2005) 56, 56-8, citing Hugo et al 'Rethinking the ASGC: Some Conceptual and Practical Issues' (Monograph Series 3, National Key Centre for the Social Application of Geographic Information Systems, University of Adelaide, 1997).
} 
identify if they lived in "the bush", ; it may be simply a matter of having a picture in mind of what rural Australia looks like, knowing it when you see it. ${ }^{9}$

\section{The Issue, Version 1: \\ 'The ability of those living in country Australia to obtain access to justice ... [is being] significantly hampered' ${ }^{10}$}

Framing the issue this way emphasises 'access to justice', and raises the implicit issues of how that idea is defined and measured.

In the many inquiries and reports in Australia on 'access to justice', ${ }^{11}$ the idea is broadly understood as access to law — justice being, in effect, "justice

\footnotetext{
${ }^{8}$ Margaret Alston and Jenny Kent, 'The Impact of Drought on Secondary Education Access in Australia's Rural and Remote Areas: A Report to DEST and the Rural Education Program of FRRR' (Research Report, Centre for Rural Social Research, Charles Sturt University, 2006) 36.

9 See, eg, Stewart J in Jacobellis v Ohio, 378 US 184 (1964) who famously said (of pornography), 'I shall not today attempt further to define ... [it]; and perhaps I could never succeed in intelligibly doing so. But I know it when I see it ...'.

${ }^{10}$ John Corcoran, 'Legal Life 2020: Rural Lawyers Will Become a Dying Breed' Lawyers Weekly, 17 September 2009.

${ }^{11}$ See, eg, Senate Legal and Constitutional References Committee, Parliament of Australia, Legal Aid and Access to Justice (2004); Senate Legal and Constitutional References Committee, Parliament of Australia. Inquiry into the Australian Legal Aid System (Third Report) (1998); Senate Legal and Constitutional References Committee, Parliament of Australia. Inquiry into the Australian Legal Aid System (Second Report) (1997); Senate Legal and Constitutional References Committee, Parliament of Australia, Inquiry into the Australian Legal Aid System (First Report) (1997); Senate Legal and Constitutional References Committee, Parliament of Australia. The Cost of Justice - Checks and Imbalances: The Role of Parliament and the Executive (Second Report) (1995); Senate Legal and Constitutional References Committee, Parliament of Australia. The Cost of Justice - Foundations for Reform (1993); Senate Legal and Constitutional References Committee, Parliament of Australia, Cost of Legal Services and Litigation - Legal Aid 'For Richer and for Poorer', Discussion Paper No 7, (1992); Joint Committee of Public Accounts and Audit Title, Parliament of Australia, Report 403: Access of Indigenous Australians to Law and Justice Services (2005); House of Representatives Standing Committee on Aboriginal Affairs, Parliament of Australia, Aboriginal Legal Aid (1980); Attorney General's Department, Parliament of Australia, Review of the Commonwealth Community Legal Services Program (2008); Australian Law Reform Commission, Managing Justice: A Review of the Federal Civil Justice System, Report No 89 (2000); Australian Law Reform Commission, Part III (Access to Justice), Equality before the Law: Justice for Women, Report No 69 (1994); Attorney General's Department, The Justice Statement, May 1995 $<$ http://www.austlii.edu.au/austlii/articles/scm/jcontents.html $>$; Access to Justice Advisory Committee, Parliament of Australia, Access to Justice: An Action Plan (1994); National Legal Aid Advisory Committee, 'Legal Aid for the Australian Community' (Research Report,
} 
according to law'. ${ }^{12}$ The idea of 'access to justice' is, therefore, the capacity to understand the law, to get legal advice, to get legal assistance and representation, and to use public legal institutions such as the courts. It requires an ability to, for example, understand, communicate, travel, and pay, and also requires the means to overcome the inability to do any of those things.

These threshold requirements for access to justice are not peculiar to rural Australia. In this framing of the issue, the whole debate about access to justice, explored in the references at note 11 above, can be taken as given: access to justice is challenging for people wherever they live, because of its cost, law's complexity, and people's own compromised abilities. The real emphasis in this framing of the issue is, therefore, on the way that the usual reasons why access to justice is problematic are differently or especially problematic for 'those living in country Australia'. As framed, the proposition is that, however high the threshold requirements are for people's access to justice generally, they are high to a 'significant' degree in rural Australia.

A risk that attaches to framing the issue of rural legal services as one of 'access to justice' is that it may narrow the focus to the situation of people who are poor, and disadvantaged and marginalised in their access to services generally. That is a consistent and at times predominant focus in access to justice research and policy in Australia which, while warranted, is not all that that access to justice is concerned with. If access to justice is access to law, then the availability of private legal services for the general community, including business, is as much a concern as the availability of public legal services for the poor, disadvantaged and marginalised. Obtaining access to justice is about obtaining access to

preventative or administrative support services, such as family law and estate advice, advice as to ... general legal rights and obligations, or any of the other non-urgent and perhaps non-critical needs of people that are typically met through the use of legal advice... ${ }^{13}$

\footnotetext{
National Legal Aid Advisory Committee, 1990); National Legal Aid Advisory Committee, 'Funding, Providing and Supplying Legal Aid Services'(Research Report, National Legal Aid Advisory Committee, 1989).

${ }^{12}$ See, eg, Address by Sir Owen Dixon upon Taking the Oath as Chief Justice of the High Court of Australia (1952) 85 CLR xi; Roscoe Pound, 'Justice According to Law', (1914) 1:3 The Mid-West Quarterly, 223. See also Economides and Blacksell, above n 1, who speak of 'access to legal services, and, by implication, to justice': at 354.

${ }^{13}$ Paul Martin, Jacqueline Williams and Amanda Kennedy, 'Professional Services and Rural Services Poverty' (2011) 16(1) Deakin Law Review 57, 62.
} 
even if '[i]t is hard to be specific about what it costs a rural community to be unable to access [such services]'. ${ }^{14}$

Keeping the necessary breadth of the issue in mind, the particular rhetorical power of framing the issue as one of 'access to justice' is that it connects with a large, continuing, national conversation about the public's access to law. It reminds policy makers that there is a necessary rural dimension to the 'access to justice' discussion, and that they need to be taking account of the physical locations and circumstances of the people who seek access, and not only of the design and operation of the institutions that are designed to deliver it (such as lawyers, courts and legislation). This is what Economides calls 'rural proofing': 'subjecting all policy to scrutiny over a wide range of topics, including asking focused questions' which relate to rural dimensions of the policy. ${ }^{15}$

But 'rural proofing' cannot be done at too general a level, as there are differences among rural areas that must be taken into account. ${ }^{16} \mathrm{UK}$ researchers have noted 'some of the limitations that are inherent in the comparative approach' when trying to describe different 'ruralities':

First, differences in the development of legal, political and economic structures have served to generate significant differences in prevailing legal cultures. Secondly, heterogeneity in legal cultures finds its counterpart in a plethora of ruralities; in each country historically specific social and spatial factors have interacted to produce different sets of problems for people living in rural areas. Thirdly, differences in legal cultures and experiences of rurality are not confined to the national plain but permeate through to specific localities in a variety of complex and subtle ways. ${ }^{17}$

The same point has been made in Australia, where Giddings and others have noted that 'marked differences between and within the communities [are] important in developing an understanding of the needs of rural communities'. ${ }^{18}$ They warn that ' $[\mathrm{t}]$ his diversity is too often overlooked in the

\footnotetext{
${ }^{14}$ Ibid.

${ }^{15}$ Kim Economides, 'Strategies for Meeting Rural Legal Needs: Lessons from Local, Regional and International Experience' (2011) 16(1) Deakin Law Review 47, 55.

${ }^{16}$ For example, ' $[\mathrm{t}]$ he distinction between rural inland and rural coastal areas is a significant one in the Australian context since there are sharp differences in growth and development, and in population movements and demographics': Alston, above n 5, 196.

${ }^{17}$ Mark Blacksell et al, 'Legal Services in Rural Areas: Problems of Access and Local Need' (1988) 12(1) Progress in Human Geography 47, 53, citing A Sayer, 'The Difference That Space Makes', in D Gregory and J Urry (eds), Social Relations and Spatial Structure (Macmillan, 1985) 49.

${ }^{18}$ Jeff Giddings, Barbara Hook and Jennifer Nielsen, 'Legal Services in Rural Communities: Issues for clients and lawyers' (2001) 26(2) Alternative Law Journal, 57, 57.
} 
methods of policy makers and city-based service providers', and that 'there has developed a tendency to perceive those in rural communities as having uniform characteristics and therefore uniform needs'. ${ }^{19}$ As a result, '[t]he cultural diversity of rural communities - in terms of ethnic and/or religious background, sexual orientation, ability, age, gender and so on - is not reflected in the range of services provided'. ${ }^{20} \mathrm{UK}$ researchers point out that:

[f]uture research ought, therefore, to be concentrated on defining more precisely the multiplicity of legal cultures that exist. To what extent do rural environments, with their sparse populations and generally poor levels of accessibility, actually exhibit distinctive features in terms of legal needs and expectations? How far do these vary between different cultures, different legal traditions and with different forms of delivery for legal services? ${ }^{21}$

They emphasise that 'such differences do exist', but note that 'as yet, there is no framework for studying them ...'.22

\section{The Issue, Version 2:}

'The number of lawyers in RRR areas is falling' ${ }^{23}$

This framing of the issues focuses on the number of lawyers working in rural legal practices. The point is illustrated by the Law Council of Australia's 2009 report which found that 'many ... sole practitioners ... will retire in the next five to 10 years', and that younger lawyers are unlikely to commit to stepping in. $^{24}$

At its simplest, this framing of the issue is simply a quantitative claim: there are fewer rural lawyers now than there once were. There are data on the number of rural lawyers in Australia, although there are caveats about its accuracy, discussed below. Research by Urbis Keys Young based on NSW Law Society data shows that while the actual numbers of rural solicitors and

\footnotetext{
${ }^{19}$ Ibid 57.

${ }^{20}$ Ibid 58.

${ }^{21}$ Blacksell et al, above n 17, 60 .

22 Ibid 60.

${ }^{23}$ Trish Mundy, Recruitment and Retention of Lawyers in Rural, Regional and Remote NSW: A Literature Review (Research paper, Northern Rivers Community Legal Centre, 2008) 5.

${ }^{24}$ Corcoran above n 10, commenting on Law Council of Australia and Law Institute of Victoria 'Report into the Rural, Regional and Remote Areas Lawyers Survey' (Research Report, Law Council of Australia and Law Institute of Victoria, July 2009).
} 
rural firms have risen, the relative rate at which lawyers practise in rural rather than urban areas has fallen by a small amount, but not by much. ${ }^{25}$

Depending on the actual boundaries that are drawn around 'rural', the total number of rural lawyers may not in fact be falling; data from the Australian Bureau of Statistics (ABS) suggest an inference that the number of lawyers in rural areas across Australia remained roughly the same in the period 20022008: 'At the end of June 2002, 79\% of all solicitor practices were located in capital cities', while '[a]t the end of June 2008 ... 78.2\% of [legal services] were located in capital cities' ${ }^{26}$ The principal problem with measuring the number of lawyers in rural Australia is one of definition. And, as I describe in more detail below when placing caveats on the data, there are inconsistencies in what is being counted, across jurisdictions and researchers, and over time.

But this framing of the issue is, of course, not simply a quantitative claim; the intended implication is that a falling number of lawyers is itself problematic. The falling number (assuming it can be consistently measured) is seen as heading towards, or as having reached, a level which is of concern because it is, as the next framing of the issue puts it, a 'shortage'. But, staying for the moment with the question of measurement, the following discussion of a 'shortage' makes clear that a simple measure of the numbers of lawyers in rural Australia doesn't tell us much that is useful. If the numbers are to be a constructive foundation for analysis, then they have to be understood in a context, most obviously that of the population. The numbers of rural lawyers must be reported along with the numbers of the rural population. Nor are aggregated numbers very useful: we need to know where in rural Australia the lawyers and the population are, and what their relevant characteristics are.

On the question of where the rural lawyers are, my research suggests that the movement of lawyers within rural Australia is at least as noticeable a phenomenon as lawyers leaving rural Australia. I explore in the next section the importance of knowing the relevant characteristics of rural lawyers and populations.

\footnotetext{
${ }^{25}$ Urbis Keys Young, 'The Solicitors of New South Wales in 2015 - Final Report' (Research Report, Law Society of New South Wales, 2004) Tables 11 and 12.

${ }^{26}$ Australian Bureau of Statistics, 8667.0 - Legal Practices, Australia, 2001-02; Australian Bureau of Statistics, 8667.0 - Legal Services, Australia, 2007-08. For 2008, the term 'legal services' included 'solicitor firms, patent attorney businesses, service/payroll entities and businesses providing various legal support services'. See the caveat about Australian Bureau of Statistics data on lawyers at $\mathrm{p} 41$ below.
} 


\section{The Issue, Version 3: \\ 'There is 'a significant shortage of solicitors willing to work in RRR areas' ${ }^{27}$}

This framing of the issue has two parts to it. The first picks up on the previous framing of the issue, and characterises any fall in the number of lawyers as a 'shortage'. The second part is concerned with lawyers' willingness to work (and live) in rural Australia.

\section{A Shortage of Solicitors}

A fall in the number of rural lawyers is a statistical phenomenon which tells us very little about access to law in rural Australia. There does not seem to be any 'right' or sufficient number in the abstract, or an obviously useful benchmark such as historical levels, future assessed need, proportion of population and so on. Even if we put the fall in numbers in the context of the surrounding population, and see that there is a drop over time in the proportion of lawyers in the rural population, ${ }^{28}$ it is difficult to say what can usefully be inferred from this. It does not necessarily indicate that people have less access to a lawyer; it is possible, for example, that, with good skills and management, fewer lawyers than was previously the case can meet the legal needs of a population.

A much more refined picture of rural lawyers and their communities is necessary. Research in England, for example, suggests a correlation between lawyers' presence in a rural town and factors such as the availability of for-

\footnotetext{
${ }^{27}$ Mundy, above n 22, 5. See also Liz O'Brien, Judy Harrison and Rachna Muddagouni, 'A Feasibility Study for Law Graduate Legal Practice Experience with Community Legal Centres in Regional, Rural and Remote Australia' (Paper presented at National Rural/Regional Law and Justice Conference, Deakin University School of law, 19-21 November 2010 $<$ http://www.deakin.edu.au/buslaw/law/rrjc/abstracts/harrison.php) 3; Glenn Ferguson, 'Bush Lawyers: The Problem Facing Regional And Rural Queensland' (2004) 24(11) Proctor 8, cited in Caroline Hart, 'Sustainable Regional Legal Practice: The Importance of Alliances and the Use of Innovative Information Technology in Regional Rural and Remote Queensland' (2011) 16(1) Deakin Law Review 225, 225 n 1.

${ }^{28}$ As my research does, reported below. See also the 2009 snapshot of the proportion of lawyers in the rural population in Suzie Forell, Michael Cain and Abigail Gray, 'Recruitment and Retention of Lawyers in Regional, Rural and Remote NSW' (Research Report, Law and Justice Foundation of NSW, September 2010) 120-122 <http://www.lawfoundation. net.au/ljf/site/articleIDs/53FAC0137BED4F38CA2577BA0024256B/\$file/Recruitment_and_ retention_of_lawyers_in_RRR_NSW_web.pdf $>$.
} 
profit work and the extent to which the particular town is a rural centre. ${ }^{29}$ Further research in Australia would identify, for example, the areas of specialty of lawyers in particular rural areas under study (commercial leasing, property and business transfers, family law, wills and estates, personal injury and so on) and, say, the amount of legal aid work do they do. ${ }^{30}$ Similarly, the population statistics for the particular rural area can be refined according to factors such as sex, age, income, first language, and home ownership, and the wide term 'rural' can be broken down into smaller parts according to factors such as town population size, degree of 'ruralness' (eg remoteness), ${ }^{31}$ proximity to the coast, ${ }^{32}$ and the presence of different types of industry. In this way one can start to say which different population groups are (or are not) served by rural lawyers, rather than assert that any measurable fall in the number of rural lawyers is self-evidently a shortage. Understanding different population groups that may seek legal services is a step towards measuring legal need, which is squarely addressed below, in the next framing of the issue.

Although there is no 'right' or sufficient number of lawyers in the abstract, some considerations suggest a benchmark for sufficiency in numbers. One such consideration is 'choice of lawyer': it is desirable — though not necessary - that there are enough lawyers to enable a person to choose one on criteria such as sex (a woman wanting to see a female lawyer, for example), language spoken or cultural affinity (migrant clients wanting to consult in their own language, for example), and willingness to take on legal aid matters. Another consideration is that it is highly desirable, if not necessary, that there are enough lawyers to make conflicts of interest manageable: 'In small towns with a very small number of private lawyers, conflict of interest and concern about anonymity are significant issues that result in many people travelling ... to access a private lawyer. ${ }^{33}$ Even if other

\footnotetext{
${ }^{29}$ Charles Watkins, Mark Blacksell and Kim Economides, 'The Distribution of Solicitors in England and Wales' (1988) 13(1) Transactions of the Institute of British Geographers, New Series 39, 52, citing K Foster, 'The Location of Solicitors' (1973) 6 Modern Law Review 153 L Bridges et al, Legal Services in Birmingham, University of Birmingham Institute of Judicial Administration, Birmingham, 1975, 18, and The Benson Report: Royal Commission on Legal Services, HMSO London, 1979, vol 1, 48.

${ }^{30}$ As done in in Forell et al, above $n$ 28, 63-77.

${ }^{31} \mathrm{See}, \mathrm{eg}$, the measures at $\mathrm{n} 7$ above.

${ }^{32}$ See $\mathrm{n} 16$ above.

${ }^{33}$ UnitingCare: Cutting Edge and Advocacy and Rights Centre Limited, 'Access to Justice in the Goulburn Valley: Responding to Unmet Legal Need through Community Legal Services' (Discussion Paper, UnitingCare: Cutting Edge and Advocacy and Rights Centre Limited, October 2008) $24 \quad<$ http://www.communitylaw.org.au/loddoncampaspe/cb_pages/ images/Discussion\%20Paper\%20Final.pdf $\$$.
} 
indicators suggest that a simple fall in the number of lawyers is not itself problematic, it will be problematic if the fall is to a level which negates choice, and which invites conflicts of interest.

\section{$2 \quad$ Willingness to Work in Rural Areas}

The unwillingness of lawyers to work in rural areas is suggested by the Law Council of Australia's 2009 report which found that 'younger lawyers ... intend to practise in [rural] areas for less than two years'. ${ }^{34}$

To understand lawyers' (un)willingness to live in rural Australia means having to investigate 'upstream factors' ${ }^{35}$ of, for example, legal education, lawyer recruitment, staff retention, business models and profitability, and rewards and incentives. There has been support for financial inducements such as the Zone Tax Offset scheme, ${ }^{36}$ and a rebate or waiver of Higher Education Contribution Scheme payments, ${ }^{37}$ although such proposals seem to have attracted limited political support. ${ }^{38}$ If these proposals are to have real appeal they need to be supported by a deeper understanding of why lawyers choose to live in rural Australia, and why they leave. ${ }^{39}$ Martin et al propose, for example, that the absence of professional networks and support may be a reason for lawyers leaving rural areas. ${ }^{40}$ As well, account must be taken of the many life choice variables which make rural life attractive and viable (or not), such as housing, transport, schooling, recreation, culture, safety and so on. ${ }^{41}$

\footnotetext{
${ }^{34}$ Corcoran above n 24.

${ }^{35}$ O'Brien, Harrison and Muddagouni, above note 27, 3 .

${ }^{36}$ Discussed in Mundy, above n 23, 23.

${ }^{37}$ Discussed in ibid 24.

38،Lawyers Slam Neglect of Rural Lawyers', The New Lawyer, 9 August 2010 $<$ http://www.thenewlawyer.com.au/article/lawyers-slam-neglect-of-rural-lawyers/521761. aspx $>$.

${ }^{39}$ Hart's qualitative research among 30 Queensland practitioners is a significant step in this direction: Caroline Hart, 'Sustainable Regional Legal Practice: The Importance of Alliances and the Use of Innovative Information Technology in Regional Rural and Remote Queensland' (2011) 16(1) Deakin Law Review 225.

${ }^{40}$ Martin, Williams and Kennedy, above $\mathrm{n} \mathrm{13,62.} \mathrm{See} \mathrm{also} \mathrm{the} \mathrm{discussion} \mathrm{of} \mathrm{the} \mathrm{need} \mathrm{for}$ professional development support for rural lawyers in Amanda Kennedy and Stephen Winn, 'Using Technology to Increase Support for Rural and Regional Legal Professionals' (2011) 16(1) Deakin Law Review 209.

${ }^{41}$ See, eg, Mundy, above n 23, 8. See also the personal account of a young city lawyer who took up rural practice in Kim McFarlane, 'Attracting Graduates to Regional and Rural Australia: A Personal Experience' (Paper presented at the National Rural/Regional Law and Justice Conference, Deakin University School of Law, 19-21 November 2010, $<$ http://www.deakin.edu.au/buslaw/law/rrjc/papers/mcfarlanekim.pdf $>$.
} 
The Law and Justice Foundation research found that factors affecting a choice to live in a rural area include family considerations, the nature of the work, professional development opportunities, the opportunity to save money, and lifestyle, including social and community networks. ${ }^{42}$ Giddings, Hook and Nielsen record 'aspects of rural legal practice that some lawyers find very attractive', quoting a Western Australian lawyer's view that rural lawyers face 'far less difficulties with bad debts, citing as the reason for this the inherent honesty of country folk' ${ }^{43}$ It seems that 'few rural lawyers ... had difficulties finding administrative staff and most enjoyed the casual country lifestyle [with] significant opportunities for relatively inexperienced lawyers who can assume major practice responsibilities at a relatively early stage of their careers' ${ }^{44}$ Similar sentiments were expressed in England, where some lawyers 'prefer[red] to forgo the high status within the profession, for the sake of "high status within a small town community", a greater likelihood of achieving partnership, ${ }^{45}$ and factors such as "the attractiveness of the countryside, the relatively cheap housing or the lack of long distance commuting, ${ }^{46}$

At the same time, it seems that the attraction of rural legal practice may vary according to where the practice is. The Law and Justice Foundation research reports that in the more remote rural regions, away from the coast and rural centres, lawyers deal with challenging clients, high volume and stressful work, adverse work environments, remoteness from supervision and support, and distance from social and family networks. ${ }^{47}$

\footnotetext{
${ }^{42}$ Michael Cain and Suzie Forell, 'Recruitment and Retention of Lawyers in Regional, Rural and Remote New South Wales: Summary Report' (Justice Issues, Paper 13, Law and Justice Foundation of NSW, September 2010) 9. This paper summarises Forell, Cain and Gray, above note 28.

${ }^{43}$ Giddings, Hook and Nielsen, above n 18, 60, citing B Chestnutt, 'A Country Practice' (1999) 26(4) Brief 5.

${ }^{44}$ Ibid, citing J Faine, Lawyers in the Alice: Aboriginals and Whitefellas' Law (Federation Press, 1993). See also the 'case studies' of lawyers choosing to practise in rural Australia: Law Council of Australia, Case Studies, RRR Law < www.rrrlaw.com.au/why-practise-in-rrrareas/case-studies/>.

45 But see scientists' and doctors' concerns about limited professional development opportunities in rural Australia, in sources cited by Martin, Williams and Kennedy, above n 13,65 .

${ }^{46}$ Watkins, Blacksell and Economides, above n 29, 52-3.

${ }^{47}$ Cain and Forell, above n 42, 8.
} 


\section{Social Capital}

Related to the phenomenon of lawyers leaving rural areas is the effect of their departure on the rural communities they leave behind. It has been suggested that a lack of legal services puts ' $[\mathrm{t}] \mathrm{he}$ future of [rural] ... communities ... in serious doubt' ${ }^{48}$ This connects with the significant amount of research that has been done into the decline of rural professional services generally, ${ }^{49}$ and the importance to rural Australia of the loss of social capital ${ }^{50}$ (attributed in large part to neoliberal, market-driven policies) $)^{51}$, although there is remarkably little reference in the research to the decline in legal services and to lawyers' contribution to social capital. ${ }^{52}$

Lawyers have a recognised place in the civic identity and economic viability of rural communities: 'well beyond the delivery of specific services to particular clients, [lawyers are] catalysts and supporters of a variety of types of innovation in communities, and ... contribut[e] to the fabric of respect for law that is at the heart of civil society'. ${ }^{53}$ As Martin et al observe, the loss of legal practitioners 'is felt in the fabric of the community, as is the absence of a doctor, nurse, accountant or any of a number of other professionals that are part of the "normal" composition of more urban communities'. ${ }^{54}$ There is therefore a strong public policy argument to be made for maintaining rural legal practices as integral to civic identity in rural towns.

\footnotetext{
${ }^{48}$ Corcoran, above $\mathrm{n} 10$.

${ }^{49}$ Hart, above n 39, 225, 225-6 and the references cited there.

${ }^{50}$ See, eg, Margaret Alston, 'Social Capital in Australia', (2002) 12 (2) Rural Society 93; Margaret Alston, 'Inland Rural Towns: Are They Sustainable?' (Paper presented at the Academy of the Social Sciences Session on Rural Communities at the Outlook 2002 Conference, Canberra 5-7 March 2002) <http://www.assa.edu.au/programs/workshop/ workshop.php?id=60>; Andrew Woodhouse, 'Social Capital and Economic Development in Regional Australia: A Case Study (2006) 22 Rural Studies 83; and interviewees' comments in Alston and Kent, above n 8, 136-8.

${ }^{51}$ Alston, 'Inland Rural Towns: Are They Sustainable?' above n 50, 8; Alston, above n 5, 1979; Matthew Tonts and Fiona Halsam-McKenzie, 'Neoliberalism and Changing Regional Policy in Australia' (2005) 10(3) International Planning Studies 183, 189.

${ }^{52}$ See, eg, Woodhouse, above n 50; Alston, 'Social Capital in Australia', above n 50. Woodhouse refers to the proportion of the population having a degree as relevant to assessing a rural town's economic development: at 87. Alston refers to research which, when reporting on loss of services in a rural town as loss of social capital, mentions the departure of a solicitor, in a list that includes a café, a bakery and two clothing shops: at 99.

${ }^{53}$ Martin, Williams and Kennedy, above n 13, 64.

${ }^{54}$ Ibid 65 . See also the discussion of affordability of lawyers below.
} 


\section{The Issue, Version 4: \\ People can't get legal help for their particular problem ${ }^{55}$}

This framing of the issue focuses on legal need, and is closely connected to any assessment of a 'shortage' of lawyers': a measure of legal need is a factor against which one can say whether there is a shortage.

A person's being unable to get legal help for a particular problem is ostensibly a legal need, although even this can be debated. ${ }^{56}$ Whether the person's circumstances give rise to a 'legal' need depends on whether the person sees the problem as a 'legal' one, ${ }^{57}$ and what non-legal services could be as effective in meeting the need. The same question must be asked of rural legal need in Australia as was asked in the UK some years ago: whether 'formal legal services are supplanted by other sources of advice in rural areas'. 58

Research being done by the NSW Law and Justice Foundation ${ }^{59}$ is developing a much better idea of where people have needs for legal help on particular issues. More importantly, however, it is demonstrating the complexity of identifying legal need, and the importance of empirical data on local circumstances to confidently identify the need.

The NSW Law and Justice Foundation's research meets a 2004 Senate recommendation for a 'national survey of demand and unmet need for legal services' ${ }^{60}$ But research such as this (and inquiries such as the Senate's) are usually concerned with those areas of law in which - or those populations for whom - public legal services will be provided through legal aid,

\footnotetext{
${ }^{55}$ Mundy, above $\mathrm{n} 23,5$.

${ }^{56}$ See the discussion in Louis Schetzer, Joanna Mullins and Roberto Buonamano, 'Access to Justice \& Legal Needs - A Project to Identify Legal Needs, Pathways and Barriers for Disadvantaged People in NSW. Background Paper' (Background Paper, Law and Justice Foundation of NSW, 2002) 5-6 <http://www.lawfoundation.net.au/report/background $>$.

${ }^{57}$ Loretta de Plevitz and Heron Loban, 'Access To Information on Civil Law for Remote and Rural Indigenous Peoples' (2009) 7(15) Indigenous Law Bulletin 22, 22, citing the Miwatj Aboriginal Legal Service, Submission to the Senate Legal and Constitutional References Committee, Inquiry into Legal Aid and Access to Justice, 2003.

${ }^{58}$ Economides and Blacksell, above n 1, 354.

${ }^{59}$ Eg, Quantitative Legal Needs Survey - Bega Valley (Pilot) (2003); The Legal Needs of Older People in NSW (2004); No Home, No Justice? The Legal Needs of Homeless People in NSW (2005); On the Edge of Justice: The Legal Needs of People with a Mental Illness in NSW (2006); Justice Made to Measure: NSW Legal Needs Survey in Disadvantaged Areas (2006), all published by the NSW Law and Justice Foundation.

${ }^{60}$ Senate Legal and Constitutional References Committee, Parliament of Australia, Legal Aid and Access to Justice (2004) Recommendation 3.23.
} 
community legal centres or organised pro bono practices. ${ }^{61}$ It is much less concerned with those areas of law for which legal services are privately purchased. Even when looking at the private legal profession, the NSW Law and Justice Foundation's research, for example, was concerned with only those private solicitors who were 'delivering legal services to disadvantaged people in regional areas through assigned legal aid case work'. ${ }^{62}$

Additional funding for legal services in rural areas is similarly directed to public, not private, legal services. For 2010-11 the Australian government announced \$154 million additional funding to enhance 'access to justice' in rural and regional areas 'for legal aid commissions, community legal centres and Indigenous legal services'. ${ }^{63}$ As I noted above, there is limited political support for financial incentives to promote private rural legal services.

Research and policy in the area of access to justice commonly focus on public legal services for the poor, disadvantaged and marginalised. This is at the expense of developing a better understanding of the difficulties faced by the general community, including business, in its access to private legal services. There is little planning around the presence, spread and availability of private legal services, ${ }^{64}$ presumably on the assumption that the operation of the market will result in an appropriate allocation of those legal resources. ${ }^{65}$ As a result, this framing of the issue encompasses work that is being done on the need that particular groups of people (those dependent on public legal

${ }^{61}$ See, eg, the reports above $\mathrm{n} 11$; UnitingCare, above $\mathrm{n} 33$.

${ }^{62}$ Cain and Forell, above n 42, 266. See similarly, John Dewar et al, Griffith Legal Aid Report: The Impact of Changes in Legal Aid on Criminal and Family Law Practice in Queensland, cited in Hart, above n 39, $226 \mathrm{nn}$ 5, 7-8.

${ }^{63}$ Australian Government, Budget Highlights 2010-11 for Rural and Regional communities, Improving Access to Justice - Legal Assistance Priorities, Budget Highlights 2010-11 $<$ www.budget.gov.au/2010-11/content/ministerial_statements/rural_and_regional $/ \mathrm{html} / \mathrm{ms}$ _rural_and_regional-02.htm>. See also, Jane Stewart and Lex Payne, 'The WA Country Lawyers Program: Addressing Vacancies in Regional and Remote WA' (Paper presented at National Rural/Regional Law and Justice Conference, Deakin University School of law, 1921 November 2010) and their discussion of the WA Country Lawyers Program 'to address the critically high number of legal vacancies in the regional community legal sector' $<$ http://www.deakin.edu.au/buslaw/law/rrjc/papers/paynealexander.pdf>; O’Brien, Harrison and Muddagouni, above n 27 and their discussion of the NACLC, RRR, CLC Law Graduate Program which promotes placement opportunities in rural community legal centres.

${ }^{64}$ There are, however, efforts to promote private legal practice as a career option in rural Australia through a joint 'marketing campaign' by the Law Council of Australia, the Australian Government and the National Association of Community Legal Centres: see $<$ www.rrrlaw.com.au $>$. In addition, a consequence of the NACLC RRR CLC Law Graduate Program seems to be some interest among graduates in working in rural private legal practice: O'Brien, Harrison and Muddagouni, above n 27, 28-9.

${ }^{65}$ This is particularly so since the advent of national competition policy: see the discussion at note 91 below. 
services) have for legal help for a particular type of problem (such as family law, crime, and debt), but it highlights that an understanding of legal need in rural areas more generally has to encompass the full range of issues for which a person commonly seeks legal assistance.

\section{The Issue, Version 5:}

Country people have to travel further to see a lawyer ${ }^{66}$

Framing the issue this way focuses on the limitations on rural infrastructure, principally concerned with distance, transport and communications. Limitations on rural infrastructure in Australia are notorious, ${ }^{67}$ and 'research ... demonstrates conclusively that there are special problems of access for those living in remote rural areas'. ${ }^{68}$

The barrier posed by poor transport and communications infrastructure is not unique to legal services. ${ }^{69}$ But the fact that it is a legal service for which distance and poor infrastructure is a barrier does give a specific dimension to the issue. Coverdale reports that '[d]istance was one of the impediments to accessing the justice system most frequently raised by survey participants and interviewees', ${ }^{70}$ noting, for example, that ' $[\mathrm{t}]$ he lack of suitable public transport services in regional Australia ... compounds court access issues for regional communities'. ${ }^{71}$

As the previous section illustrated, however, people seeking legal services are not a single group with like needs, and the infrastructure barrier will be more or less a concern depending not only on income, age, and ability, but also on the type of legal matter. It is appropriate to take a step back and ask, as Economides and Blackwell did, 'Do problems of physical accessibility affect the use made of legal services by those living in rural areas and, if such

\footnotetext{
${ }^{66}$ UnitingCare: Cutting Edge and Advocacy and Rights Centre Limited, above n 33, 24; Corcoran, above $\mathrm{n} 10$.

${ }^{67}$ Giddings, Hook and Nielsen, above n 18, 58, and citing Rosemary Hunter, Family Law Case Profiles, Justice Research Centre, 1999, xiv: : at $61 \mathrm{n}$ 46. See also, Taskforce on Regional Development, Developing Australia: A Regional Perspective (AGPS, 1993).

${ }^{68}$ Blacksell et al, above n 17, 60 .

${ }^{69}$ See, eg, Margaret Alston and Jenny Kent, above n 8, 32.

70 Richard Coverdale, 'Postcode Justice: Rural and Regional Disadvantage in the Administration of the Law' (2011) 16(1) Deakin Law Review 155, 163.

${ }^{71}$ Ibid 165.
} 
problems do exist, to what extent are they absolute or culturally determined ...?'. ${ }^{72}$ Many, if not most, commercial legal matters, for example, can be managed remotely — assuming adequate technology — as can some personal matters, and many matters require only one, or only an occasional, lawyer/client meeting. On the other hand, the occasion in a lawyer/client relationship which is most challenged by the simple physical inaccessibility of a lawyer is the initial approach by a personal and one-off client. A person's first contact with a lawyer can be spontaneous, and can follow a long period of anxiety, uncertainty and vacillation. Having to travel to make that first contact is a real barrier to doing it all.

One way of seeing the obstacles posed by inadequate rural infrastructure is as obstacles to lawyers' business: every person who doesn't make it to a lawyer is a client the lawyer misses out on. ${ }^{73}$ While the business end of the lawyerclient relationship is not the point of this article, that perspective suggests questions that can be asked of the rural infrastructure issue: how have lawyers and their modes of practice adapted to overcome what is, for them, an obstacle to their doing business? Has the market caused lawyers to innovate to connect with a client who is otherwise separated by distance?

Embedded in this framing of the issue is the conventional model of a client's having to travel to the lawyer. While it has never been a lawyer's professional habit, as it was once a doctor's and is still an accountant's, to go to the client, it may be that some lawyers do provide 'peripatetic services' ${ }^{74}$ To some unknown extent, rural lawyers may be accessible to their clients through branch offices, ${ }^{75}$ through operating local clinics, and through innovative use of electronic communications. ${ }^{76}$ If so, then, from the perspective of access to legal services, there is some good news, but it needs further research.

\footnotetext{
${ }^{72}$ Economides and Blacksell, above n 1, 354 (emphasis added).

${ }^{73}$ It was this realisation that caused previously hostile private practitioners to accept the presence of community legal centres in Australia: not only do the centres assist people who present with problems, or a demeanour, that private practitioners do not want to deal with, the centres refer to private practitioners people who can pay and only need a prompt in the right direction.

${ }^{74}$ Economides and Blacksell, above n 1, 370 .

${ }^{75}$ Giddings, Hook and Nielsen, above n 18, 61. Branch offices have been noted as a possibility but are not identified in the Law Justice Foundation data: Cain and Forell, above n 42, 1-16.

${ }^{76}$ See the discussion of rural practitioners' use of information technology in Hart, above n 39, $249-51$.
} 


\section{The Issue, Version 6: \\ Lawyers in rural areas are less willing than they were to take on legal aid work ${ }^{77}$}

This framing of the issue focuses on the amount of legal aid work done by rural lawyers. It assumes, however, that rural lawyers did once take on more legal aid work than they do now. This assumption is made in the absence of any published data about changing rates, over time, of grants of legal aid to rural lawyers. As well, it is unclear what aspect of 'legal aid work' is being quantified: it may be that there are fewer lawyers taking on the same amount of legal aid work, or that there more lawyers taking on legal aid work but taking on less of it overall, and so on. It may be that for some rural lawyers, with lower overheads and more modest profit expectations, taking on legal aid work is more manageable than it is for urban lawyers, in which case it is important to know where the lawyers are who are (and are not) taking on legal aid matters, and what types of practice they are running.

If, on some measure, lawyers are in fact less willing than they were to take on legal aid work, it raises the question of why that is so. The unwillingness of lawyers to accept legal aid work is not unique to rural areas, although the situation of rural lawyers may introduce particular considerations. Those considerations could go either way: it may be that lower overheads make legal aid rates less unattractive to rural lawyers than they are to urban lawyers; it may be that distance exacerbates for rural lawyers whatever cost and frustration is involved in dealing with the legal aid bureaucracy. But research is needed to establish whether there is reluctance among rural lawyers to take on legal aid work and, if so, why. That inquiry may be a larger one, for all lawyers, and one within which the circumstances of rural lawyers could be distinguished.

To understand the extent to which rural lawyers' (un)willingness to take on legal aid work is a barrier to people's access to legal services, research would need to establish what proportion of the rural population relies on legal aid for legal assistance. To a very large extent, those people will have needs in family law and criminal matters, as those matters represent most of legal aid expenditure. ${ }^{78}$ Another way of asking the research question would be: 'to what extent is crime and family law a part of the whole picture of rural legal need?'.

\footnotetext{
${ }^{77}$ Mundy, above n 23, 5 .

${ }^{78}$ In 2008/2009, 64.5 per cent of legal aid grants in Australia were made in criminal matters, 26.3 per cent were made in family law matters, and 9.2 per cent were made in 'civil' matters: National Legal Aid, 2008-2009 Financial Year to Date Statistics 'YTD Law Type', $<$ www.legalaid.tas.gov.au/nla/ reports/20082009/html/Case\%20law.html>.
} 


\section{The Issue, Version 7: \\ It is 'a question of social equity, [when] an uneven distribution of services denies some ... the ease of access to justice that others enjoy, 79}

This framing of the issue focuses on rural/urban equity. Coverdale notes that "the "great divide" between metropolitan and rural/regional Australia [has] existed and been recognised for some time'. ${ }^{80}$ Framing the issue in this way assumes that there is a measure of what is 'equitable'. By what criteria will rural and urban populations be on the same footing? By what characteristics can comparable rural and urban populations be identified?

It seems hard to resist the rhetorical call for equity of access to legal services as between urban and rural areas: it seems unfair that if you can get a lawyer for a type of problem in Tempe or Toorak, you cannot get a lawyer for that type of problem in Townsville or Tennant Creek. There are times when the call will be not merely rhetorical but a description of absolute inequity, if not systemic discrimination, such as when 'access to justice in remote areas [is] so inadequate that remote Indigenous people cannot be said to have full civil rights'. ${ }^{81}$ And the 'inequity' argument can go the other way. It can be said to be unfair that, if you can get a lawyer for a type of problem in Townsville or Tennant Creek for $\$ \mathrm{x}$, you cannot get a lawyer for that type of problem in Tempe or Toorak for less than twice \$x.

There is much more to the question of equity of access than simply being able to see a lawyer or not. The issue is necessarily related to the same questions of cost, distance, need, capacity and so on which inform a more general judgement about inequities between rural and urban Australia. ${ }^{82}$ This version

\footnotetext{
${ }^{79}$ Iwan Davies and Lynn Mainwaring, 'Territorial Justice and Access to Knowledge: The Distribution of High-Level Legal Skills in the Regions of England and Wales' (2007) 14(3) International Journal of the Legal Profession 237. Davies and Mainwaring distinguish the idea of social equity from an economic analysis of access to services, noting that 'economic efficiency implies nothing about social equity', and that '[i]n the economics literature an 'efficient' arrangement is one that is 'Pareto-optimal' [ie, where no-one's position could be improved without someone else's position being worsened.]': at 240. They also note that 'an economy can be Pareto-optimal and still be perfectly disgusting' quoting Amartya Sen, Collective Choice and Social Welfare (1970), 22: at 257 n 22.

${ }^{80}$ Coverdale, above n 68, 156 and the references cited there. See also Alston, above n 5, on rural health inequalities.

${ }^{81}$ de Plevitz and Loban, above n 57, 22, citing The Top End Women's Legal Service, Submission to the Senate Legal and Constitutional References Committee, Inquiry into Legal Aid and Access to Justice, 2003.

${ }^{82}$ See, eg, Brian Cheers, Welfare Bushed: Social Care in Rural Australia (Ashgate, 1998) Ch 2; Chris Sidoti, 'Bush Talks' (Research Report, Human Rights and Equal Opportunities Commission, 26 Feburary 1999).
} 
of the issue is a reminder that access to law in rural areas is a small part of the larger question of the sufficiency of rural Australia's access to a wide range of professional services.

\section{The Issue, Version 8: \\ Legal services are 'less affordable ... in rural and regional areas than elsewhere, 83}

Framing the issue in this way focuses on the cost of lawyers, in relative rather than absolute terms. It is a specific application of the 'urban/rural inequity' complaint. But there are many ways the relative cost of lawyers can be assessed.

Apart from clients who, wherever they live, simply cannot afford a lawyer, the 'affordability' of a lawyer for a rural client can be assessed by reference, for example, to the cost of like work in urban areas, or to (acceptable?) profit margins, or to rural clients' incomes or capacity to pay, and so on. These questions cannot be answered usefully in general terms, but depend on the types of law - for example, commercial, personal, public, criminal - and on the types of clients - for example, business clients, one-shot litigation clients, ${ }^{84}$ ordinary life-event clients and so forth. For some if not most types of law and clients, rural legal costs could be both cheaper in absolute terms, and more affordable than for urban counterparts.

As noted above, measuring costs is a way of assessing 'social equity', for which a simple comparison of dollar figures is not especially helpful. A comparison requires, for example, a clear and common description of what is being purchased. As well as the possibility of different levels of skill and different levels of service, there is an issue as to whether the nature of the legal work is something known only to, or best, by a local lawyer, or is work an urban lawyer could equally do. There are types of legal work, relating to land use and water rights for example, that are more likely to arise in rural areas, and aspects of rural legal practice that are different from urban legal practice, such as 'closeness of communities, the extra care needed to maintain

\footnotetext{
${ }^{83}$ Maria Karras et al, On the Edge of Justice: The Legal Needs of People with a Mental Illness in NSW, Ch 4 (2006) Law and Justice Foundation, n 86 and associated text <http://www. lawfoundation.net.au/ljf/app/9CD27111A2A8D9CBCA25718E0008FD16.html>.

${ }^{84}$ See, eg, the very influential account of the 'one-shotter' in Marc Galanter, 'Why the "Haves" Come Out Ahead: Speculations on the Limits of Legal Change' (1974) 9 Law \& Society Review 95.
} 
confidentiality of client matters and a greater likelihood of there being a conflict of interest'. ${ }^{85}$

UK researchers have 'assess[ed] whether it is meaningful to talk in terms of different legal cultures in rural, as opposed to urban, environments and whether these vary significantly between different countries and legal systems' ${ }^{86}$ They concluded that 'local legal cultures exert strong influence over the ways in which lawyers organise and run their practices, ${ }^{87}$ although 'the exact processes and practices which serve to shape local legal cultures are extremely complex and, as yet, remain in need of much more detailed elaboration'. ${ }^{88}$

In light of the importance of an 'anthropological concept of local legal cultures, which reflect the reality of the law for specific groups', ${ }^{89}$ assessing 'affordability' in a meaningful way is a complex process which requires the identification and close examination of relevant variables.

\section{The Issue, Version 9: \\ People in the country assume they can't afford a lawyer ${ }^{90}$}

This framing of the issue is a variant on the affordability complaint, and focuses on people's perception of lawyers in their community.

It may be that people in rural areas make only the same assumptions about the cost of lawyers, and as readily, as do people in urban areas, along the lines of: 'I can't afford a lawyer to do my will, and legal aid doesn't do wills, so I can't get the legal help I need'. But such an assumption suggests a view of lawyers as a profession, and more particularly of lawyers as members of the community, which is at odds with a traditional view in rural areas. It is closer to a post-National Competition Policy $(\mathrm{NCP})^{91}$ view of lawyers as people

\footnotetext{
${ }^{85}$ Giddings, Hook and Nielsen, above n 18, 57.

${ }^{86}$ Blacksell et al, above n 17, 47.

${ }^{87}$ Ibid 54.

${ }^{88}$ Ibid.

${ }^{89}$ Economides and Blacksell, above n 1, 371 (emphasis in original).

${ }^{90}$ UnitingCare: Cutting Edge and Advocacy and Rights Centre Limited, above n 33, 30.

91 'National Competition Policy (NCP) refers to those laws and regulations which are designed to "enable and encourage competition" in the supply of goods and services. Following the recommendations of the 1993 Hilmer Report into National Competition Policy, all state and territories introduced a number of reforms with the effect that uniform legislation was enacted to apply Part IV of the Trade Practices Act 1974 to the professions. These reforms essentially became operative from 21 July 1996': Mundy, above n 23, 17.
} 
operating a for-profit business, rather as professionals providing personal services. The latter view - an 'old-fashioned' one in that it pre-dates the NCP reforms - is a traditional one that still has some hold in rural communities.

As a professional, and a respected member of the civic community, ${ }^{92}$ a rural lawyer may be alert to cost as a barrier to their services, and be prepared to reduce, defer, waive or otherwise negotiate fees, to ensure that local people have access to a lawyer. This is not fanciful. Giddings, Hooke and Nielson cite Blacksell and others: 'Solicitors working as sole practitioners in rural areas may be portrayed as the last bastions of generalist, small-scale, legal practice and the custodians of true professional value'. ${ }^{93}$ They describe the important civic role that lawyers have in rural areas: 'Being 'the lawyer' in a small rural town makes you the model citizen overnight', a status which requires 'balanc[ing] the service ideal with making a living,. ${ }^{94}$

The professional ethic of a rural lawyer was well-expressed by solicitor Bill Thomson of Coolamon, who is concerned that the "pro bono work carried out by country and small suburban practices is not being recognised'. He suggested that:

[t]he reasons behind this lack of acknowledgement are that smaller firms and practices do not have formal recording mechanisms as voluntary and pro bono work is an integral part of their practice; [local people] are comfortable enough to just drop into a small practice's office for free advice; living and working in the community, practitioners understand the challenges faced by [their community] and accordingly adjust their fees; practitioners' families mix with a wide socio-economic group and realise how important it is that if you make a quid out of a community, you've got to be prepared to put back in; and practitioners are accessible outside work hours, whether it be for advice to community meetings or general legal advice. $^{95}$

\footnotetext{
${ }^{92}$ See above nn 52-53 and the discussion of social capital.

${ }^{93}$ Mark Blacksell, Kim Economides and Charles Watkins, Justice outside the City: Access to Legal Services in Rural Britain (Longman Scientific and Technical, 1991) 4.

${ }^{94}$ Giddings, Hook and Nielsen, above n 18, 60.

${ }^{95}$ Bill Thompson, Letter: 'Pro Bono's Small-Firm Supporters' NSW Law Society Journal, July 2008.
} 
Lawyers have been integral to civic identity in rural towns, and in any assessment of access to legal services it is important to understand whether and to what extent this has changed. In fact, it may be that those lawyers who remain in rural areas carry an even stronger sense of their civic role, although that should mean that people will be less likely to assume they can't afford a lawyer, and be prepared to test the lawyer's willingness to act for a reduced, deferred, waived or otherwise negotiated fee.

The business/profession tension between service and profits suggests the larger related issue of the effect of NCP on rural lawyers, which Mundy has canvassed in some detail, ${ }^{96}$ drawing in particular on Marks, Martin and Verbeek's discussion paper for the NSW Law Society of New South Wales. ${ }^{97}$ Mundy concludes that NCP is one of a number of concurrent factors which have brought economic pressure to bear on rural lawyers, placing their practices under financial pressure.

Paterson and others in the UK have described lawyers as developing a new type of professionalism, rather than simply adopting a conventional for-profit business model. Reviewing the impact of competition reforms, they found that rural lawyers were adopting a different idea of their profession and professional role; ${ }^{98}$ they had 'succeeded in adopting new organizational modes and patterns of operations, which ... ultimately allowed [them] to deflect, colonise or reduce many potential challenges'. The rural lawyers were 'more robust and resilient' than had been thought. ${ }^{99}$

Clearly, some rural lawyers in Australia have been successful in maintaining both viable practices and professional reputations in their local community. Maybe they have been 'strategic', ${ }^{100}$ or they have found economies of scale or appropriate specialities, ${ }^{101}$ or they have made good use of strategic alliances

\footnotetext{
${ }^{96}$ Mundy, above $n$ 23, 17-18.

${ }^{97}$ Bob Marks, Paul Martin and Miriam Verbeek, 'National Competition Policy: A Discussion Paper' (Discussion Paper, Law Society of New South Wales, March 2002).

${ }^{98}$ Alan Paterson et al, 'Competition and the Market for Legal Services (1988) 14(4) Journal of Law and Society 361; Alan Paterson, 'Professionalism and the Legal Services Market (1996) 3(1-2) International Journal of the Legal Profession 137.

${ }^{99}$ Daniel Muzio, 'The Professional Project and the Contemporary Re-Organization of the Legal Profession in England and Wales' (2004) 11(1-2) International Journal of the Legal Profession 33.

${ }^{100}$ Paterson et al, above n 98.

${ }^{101}$ Giddings, Hook and Nielsen, above n 18, 61 .
} 
and information technology, ${ }^{102}$ or they have been lucky, dedicated and/or stubborn. A viable practice means that it is, to a sufficient extent, profitable. ${ }^{103}$ That means that there are clients, and so to that extent there is access to legal services. But this version of the issue is about perception: whether or not the legal practice is seen to be accessible. If, for example, it is doing well because it has a niche practice in agricultural contracts, then it may well be seen as unaffordable by many local people with 'ordinary' legal issues.

Research needs to explore not merely where the rural legal practices are doing well, but whether their success is derived from serving one group in the community, at the expense of the practice actually being, or being seen to be, unaffordable by another.

\section{Rural Legal Practices in NSW 1988-2004}

\section{A Background}

In a 1999 article $^{104}$ I reported on a survey I carried out to assess public perception of legal services in NSW, out of which a troubling picture emerged of the likely future for rural legal services. In 2004-5 I was part of a team that consulted to the State and federal governments in a review of community legal services in NSW, ${ }^{105}$ in the course of which I conducted interviews and focus groups, and reviewed data from the Australian Bureau of Statistics $(\mathrm{ABS})$, to assess the barriers to law faced by people and the nature of services that could best overcome those barriers. This introduced me to the phenomenon well known to many policy makers and researchers - that people in rural Australia have more limited access to legal services than do their urban counterparts. The temptation is to examine, immediately and urgently, why this is so, but we need first to be sure the premise is valid, and ask, 'What level of access do rural residents have to legal services?'.

\footnotetext{
${ }^{102}$ Suggested by Hart's research into the question 'how and why do some [rural] legal practices not only survive but also grow and profit, while other practices dwindle and disappear': Hart, above n 39, 228.

${ }^{103}$ On the question of what I have called viability, see the discussion of what makes a legal practice 'sustainable' in Hart, above n 39, 233-9.

${ }^{104}$ Simon Rice, 'Access to Law in the Year 2525' (1999) 24 Alternative Law Journal 62.

${ }^{105}$ Gordon Renouf, Simon Rice and Roger West, 'Review of the NSW Community Legal Centres Funding Program: Final Report (Research Report, Legal Aid Commission of NSW, June 2006).
} 
The research I report on below addresses that question in one way, by mapping the physical location of private legal practices in rural areas, and assessing the presence of private legal practices as a proportion of the population. My focus was on private practices rather than public services because of a concern that access to the former is often overlooked, ${ }^{106}$ and because identifying the location and staffing of public legal services is comparatively easy.

To answer the question, 'What access do people in rural NSW have to a private lawyer?', I mapped the presence and movement over time of private legal practices in rural NSW.

\section{B Methodology}

The membership records I was given access to cover the years 1988-2004. The NSW Law Society subsequently declined to provide access to further records on grounds of 'privacy', although I did not seek and was not given access to the names of any practitioners, and none of the data I received or have reported form a basis for inferring the identity of any lawyer in NSW. The membership data was collected from all practising solicitors in NSW, as membership was mandatory during that period. I have not collected or reported data on barristers.

The Law Society membership data was not collected for the purposes of the analysis I undertook. Unsurprisingly, therefore, it is limited in what it can offer. ${ }^{107}$ To ensure the validity of the analysis, I worked only with membership details that were available consistently for all legal practices, namely the type of practice (for example, private or government) and the location of practice. Details of solicitors relating to, say, areas of accredited specialisation, years in practice, and income brackets, were not recorded with sufficient consistency to be of use. Missing from the membership details are the records of the few practitioners who wish to keep their practice records confidential.

\footnotetext{
${ }^{106}$ See the discussion in Martin, Williams and Kennedy, above $\mathrm{n} 13$.

${ }^{107}$ I note here my gratitude to Mr Frank Siciliano for his assistance in analysing and reporting on the data.
} 
I excluded data about practice types other than private practice: corporate, government and community legal centre lawyers. I situated each private practice in a local government area (LGA), which required cross-checking where suburbs overlap LGAs, suburb names are duplicated, or suburbs are named differently from the way they are named in LGA records. Having allocated the practices according to LGAs, I removed practices in Newcastle, Sydney and Wollongong LGAs from the database, leaving only the practices in what I have treated as rural LGAs.

I matched the resulting data with $\mathrm{ABS}$ data for the total rural population (NSW, less Newcastle, Sydney and Wollongong), and the populations by LGA. The rural population figures are based on the Estimated Resident Population (ERP) which is the official ABS measure of the Australian population. It is based on the concept of usual residence, and refers to all people who usually live in Australia, except foreign diplomatic personnel and their families. It includes usual residents who are overseas for less than 12 months and excludes overseas visitors who are in Australia for less than 12 months. It is calculated for 30 June of the census year, and is updated quarterly, using administrative data relating to births, deaths, overseas migration and interstate migration. ${ }^{108}$ Relevantly for the table of data below, census years were 1986, 1991, 1996 and 2001.

The resulting picture is set out in the tables under the heading 'The Data' below.

\section{Caveats on Data on Lawyer Numbers}

For the purposes of similar research exercises into the number of rural lawyers, I note here some caveats on the reliability of the available data. In my research reported, I treat LGAs in Wollongong and Newcastle, along with those in Sydney, as urban areas, calling the remainder 'rural'. The Urbis Keys Young report ${ }^{109}$ groups lawyers by categories of 'city/suburban' and 'country' but does not publish its definition of 'country'. Presumably it uses the definition used by the NSW Law Society, which commissioned the report and

\footnotetext{
${ }^{108}$ Australian Bureau of Statistics, 2901.0 - Census Dictionary, Glossary, 2006.

${ }^{109}$ Urbis Keys Young, above n 25.
} 
provided the data. For the NSW Law Society 'country' is 'outside the Sydney Metropolitan area', ${ }^{110}$ and includes lawyers and legal practices in, for example, the large urban areas of Wollongong and Newcastle. In its data, the ABS distinguishes only between 'capital cities' and the rest; in relation to NSW, for example, 'capital city' may or may not equate precisely with the 'Sydney Metropolitan area' that the Urbis Keys Young report seems to have used.

A second caveat, which I realised when working with NSW Law Society data, is that the information reported by the Law Society is, unsurprisingly, the information that is reported to the Law Society. If there are mistakes in the forms completed and returned by practitioners, then mistakes infect the reported data. ${ }^{111}$ For example, in a spot check on data for a particular year, it was apparent that when a firm relocated, some lawyers in the firm had updated their contact details with the Law Society and some had not; the lawyers who had not were still recorded as being at a location they had in fact left. This problem might occur only when a law firm moves premises, as it can be assumed that lawyers will, in fact, change their details when changing from one firm to another.

This leads to a third caveat: the problem of relying on data not collected for the purpose. The membership data that I was working with were not collected for the purposes of research. The database is a working tool for the Law Society, primarily to record the names and contact details of its members. It serves as well to give the Law Society a general idea of where its members are and to give a profile of the membership. Quite understandably, the limited data collected do not support wide-ranging inferences about lawyers. For example, simply knowing where lawyers have said their 'place of practice' is, for the purposes of renewing their practising certificate, does not enable a researcher to say where lawyers actually practice. How close to another town or the border of a region are they? Where do they draw their clientele from? Where do they run branch offices or clinics? Do they work part-time? Do they work as well from home? These are all questions which, I have suggested above, need to be answered before one can really understand issues of rural access to law.

\footnotetext{
110 See Law Society of NSW, Country Societies <www.lawsociety.com.au/about/regional lawsocieties/countrysocieties/index.htm>.

${ }^{111}$ Similar problems were encountered by researchers when relying on the UK Solicitors and Barristers Directory: Watkins, Blacksell and Economides, above n 29, 41 and Appendix 1.
} 
A final caveat is that, while the Law Society data seem to remain constant in form and content from one year to the next, the nature of what the ABS records as 'lawyers' or 'legal practitioners' changes from time to time, making comparisons problematic, as the ABS cautions. ${ }^{112}$ In 1992-93 and again in 1995-96, the ABS reported on 'legal practices', which were barristers and solicitors. ${ }^{113}$ But in 2001-02 the ABS reported on 'legal practices' which included 'private solicitor and barrister practices, and other legal services organisations operating in Australia, whose primary activity was the provision of legal services'. ${ }^{114}$ Reference to 'other legal services organisations' included 'patent attorneys, legal aid authorities, community legal centres, government solicitors and public prosecutors'. Differently again in 2007-8, the ABS reported on 'Legal Services' (my emphasis), a broader survey which covered not only barristers and 'solicitor firms [and] patent attorney businesses', but also 'service/payroll entities and businesses providing various legal support services'. ${ }^{115}$ The Law Council is not accurate when it says that the ABS 2007-8 data is about 'Legal Practices', ${ }^{116}$ and too narrow when it describes the data as being about 'legal organisations whose main role was the provision of legal services'. ${ }^{117}$

112 'The reader should bear in mind that this survey was not designed to support accurate estimates of change over time, and as such should exercise caution when comparing the 2007-08 results to the 2001-02 results ...': Australian Bureau of Statistics, above n 26, Explanatory Note.

113 Australian Bureau of Statistics Legal and Accounting Services 8678.0 1995-96, 1; Australian Bureau of Statistics Legal and Accounting Services 8678.0 1995-96, 7.

${ }^{114}$ Australian Bureau of Statistics, 8667.0 - Legal Practices, Australia, 2001-02.

${ }^{115}$ Australian Bureau of Statistics, 8667.0 - Legal Services, Australia, 2007-08.

${ }^{116}$ Law Council of Australia, How Many Lawyers Are There in Australia? <http://www. lawcouncil.asn.au/information/about-the-profession/number-of-lawyers.cfm>.

117 Law Council of Australia, Brief Snapshot of the Legal Profession (September 2009) $<$ http://www.lawcouncil.asn.au/shadomx/apps/fms/fmsdownload.cfm?file_uuid=A770EF941E4F-17FA-D2D1-BA99625CD699\&siteName=lca $>$. 


\section{The Data}

The data is summarised in the following table.

Table 1: Rural solicitors' practices per 10000 population

\begin{tabular}{|l|c|c|c|}
\hline & Rural population & No of rural law firms & Law firms per 10 000 \\
\hline $\mathbf{1 9 8 8}$ & 1455835 & 734 & 5.0 \\
\hline $\mathbf{1 9 8 9}$ & 1475706 & 746 & 5.1 \\
\hline $\mathbf{1 9 9 0}$ & 1470179 & 764 & 5.2 \\
\hline $\mathbf{1 9 9 1}$ & 1609215 & 767 & 4.8 \\
\hline $\mathbf{1 9 9 2}$ & 1611682 & 768 & 4.8 \\
\hline $\mathbf{1 9 9 3}$ & 1615436 & 783 & 4.8 \\
\hline $\mathbf{1 9 9 4}$ & 1678932 & 779 & 4.6 \\
\hline $\mathbf{1 9 9 5}$ & 1677868 & 763 & 4.5 \\
\hline $\mathbf{1 9 9 6}$ & 1676600 & 761 & 4.5 \\
\hline $\mathbf{1 9 9 7}$ & 1669274 & 767 & 4.6 \\
\hline $\mathbf{1 9 9 8}$ & 1702957 & 765 & 4.5 \\
\hline $\mathbf{1 9 9 9}$ & 1702957 & 780 & 4.6 \\
\hline $\mathbf{2 0 0 0}$ & 1696218 & 772 & 4.6 \\
\hline $\mathbf{2 0 0 1}$ & 1773845 & 754 & 4.3 \\
\hline $\mathbf{2 0 0 2}$ & 1781612 & 763 & 4.3 \\
\hline $\mathbf{2 0 0 3}$ & 1788826 & 781 & 4.4 \\
\hline $\mathbf{2 0 0 4}$ & 1836413 & 797 & 4.3 \\
\hline
\end{tabular}

\section{$1 \quad$ Comment}

Looking down the three columns of data, a trend is apparent in each. There is a net increase in the rural population from 1988 to 2004 of a little over 26 per cent. There is a net increase in the number of rural legal practices over the same period of a little over 8.5 per cent. Clearly the population increase outstripped the increase in rural legal practices and, as a result, the proportion of legal practices per 10000 population fell by 14 per cent. 
There is an interesting volatility in the rate and direction of change in the number of rural legal practices. The number increases steadily from 1988 to 1993, drops annually until 1996, picks up a bit and plateaus in 1997 and 1998, rises sharply in 1999 but still not to 1993 levels, goes up and down within the established range in 2000-2003, and then hits a new high in 2004. This suggests that it would be rewarding to look more closely at the particular rural areas where these changes occurred and at concurrent events which may have affected movements into and out of those areas, and to interview the practitioners involved.

The areas in which the volatility occurred are apparent from a breakdown of the data by LGA. In the period 1988-2004 the number of rural LGAs varied in a range from 91 to 100, and the shifting of boundaries, creation of new LGAs and merger of existing LGAs make comparison over time very difficult for some areas. To illustrate the changing number of legal practices in areas over time, I have selected the following LGAs as ones which remained stable in their boundaries, and illustrate different rates of change. For simplicity I have marked the points of change at three yearly intervals.

To illustrate the significant difference that the departure or arrival of a single legal practice can make in rural areas, ${ }^{118} \mathrm{I}$ have noted in parentheses the number of practices in the LGA for each year.

Table 2: Rural solicitors' practices per 10000 population by LGA*

\begin{tabular}{|r|r|r|r|r|r|r|}
\hline & $\begin{array}{c}\text { Cooma- } \\
\text { Monaro }\end{array}$ & \multicolumn{1}{|c|}{ Grafton } & \multicolumn{1}{c|}{$\begin{array}{c}\text { Broken } \\
\text { Hill }\end{array}$} & \multicolumn{1}{c|}{ Cowra } & Armidale & $\begin{array}{c}\text { Coona- } \\
\text { barabran }\end{array}$ \\
\hline $\mathbf{1 9 8 8}$ & $4.2(4)$ & $4.2(7)$ & $1.2(3)$ & $3.45(4)$ & $9.7(19)$ & $2.7(2)$ \\
\hline $\mathbf{1 9 9 1}$ & $6.1(6)$ & $5.3(9)$ & $1.3(3)$ & $1.7(2)$ & $6.9(15)$ & $4.2(3)$ \\
\hline $\mathbf{1 9 9 4}$ & $6.2(6)$ & $6.3(11)$ & $1.3(3)$ & $2.4(3)$ & $6(13)$ & $2.8(2)$ \\
\hline $\mathbf{1 9 9 6}$ & $7.3(7)$ & $6.4(11)$ & $1.4(3)$ & $2.5(3)$ & $6.1(13)$ & $1.4(1)$ \\
\hline $\mathbf{1 9 9 8}$ & $7.3(7)$ & $7.5(13)$ & $1.4(3)$ & $2.4(3)$ & $7.5(16)$ & $1.5(1)$ \\
\hline $\mathbf{2 0 0 1}$ & $8.5(8)$ & $7.5(13)$ & $1.4(3)$ & $3.1(4)$ & $6(15)$ & $1.4(1)$ \\
\hline $\mathbf{2 0 0 4}$ & $9.5(9)$ & $8.2(14)$ & $2(4)$ & $2.5(4)$ & $5.7(14)$ & $1.5(1)$ \\
\hline Rate & $+135.7 \%$ & $+95.2 \%$ & $+40 \%$ & $-27.5 \%$ & $-41.2 \%$ & $-44 \%$ \\
\hline
\end{tabular}

* Numbers in parentheses are the actual number of legal practices in the LGA.

\footnotetext{
118 '... the loss of even a single solicitor for [the Far West] will have a major impact': Cain and Forell, above $n$ 42, 7.
} 
Looking only at these few LGAs, out of about 100, invites speculation that can be answered only by further data and research into the larger context.

It would seem that the Cooma-Monaro and Grafton regions, for example, have generated increasing work for lawyers over the period, enough to warrant a dramatic increase in both the number of legal practices and the proportional presence of legal practices in the population. This raises questions about the types of legal work, the profile of the population, the range of legal needs, the existence of professional networks and support, the local economy, the business models of the legal practices and so on. By way of contrast, the reverse seems true for Armidale, and one wonders what changes have caused the marked decline there in the number of legal practices and the proportional presence of legal practices in the population.

Cowra suggests a different story, where the number of legal practices has remained constant while their proportional presence in the population has decreased. Does that mean that the larger population is not generating more legal work or, if it is, is the work not especially remunerative? Or perhaps the 'new' work is of a type that is well-catered for by the established legal practices, or is being done elsewhere, outside the LGA.

While the numbers for Broken Hill suggest that not a lot has changed, that could in itself be problematic. If, for example there were not enough legal practices before, then there are still not enough now, or if the range of expertise within the legal practices did not meet legal need before, it may not now. And the persistent single practice in Coonabarabran suggests that the lawyers there may have useful observations about maintaining viability, although the same questions of actually meeting legal need could arise as they do for Broken Hill.

\section{$2 \quad$ LGAs with No Lawyers}

The Law and Justice Foundation reported that in June 2009 'there were 19 LGAs in NSW that did not have on record a single resident practising solicitor'. ${ }^{119}$ Checking my data from the NSW Law Society for the same LGAs, I can see that 14 of those 19 LGAs had no legal practice in the period 1988-2004: ${ }^{120}$ Balranald, Boorooowa, Brewarrina, Carrathool, Central Darling, Conargo, Harden, Jerilderie, Murrumbidgee, Narromine, Tumbarumba, Unincorporated NSW (Far West), Uralla, Wentworth.

\footnotetext{
${ }^{119}$ Forell, Cain and Gray, above n 28, 38 (emphasis in original).

${ }^{120}$ For which Forell, Cain and Gray propose explanations: above n 28, 38.
} 
Interestingly for the purposes of qualitative research (which would ask: 'What happened?'), the remaining five LGAs had at least one legal practice for most or all of the 1988-2004 period:

1. There were two legal practices in the Gilgandra LGA from 1988 until 1998, one in the period 1999-2002, two again in 2003, and one in 2004. At some time between 2004 and 2009 that single practice closed.

2. From 1988 until 1997 there was a legal practice in the Guyra LGA, and there were two in the period 1998-2004. At some time between 2004 and 2009 those two practices closed.

3. In the Murray LGA there were two legal practices from 1988-2004 except for 1991-95 when there was only one. The two practices closed sometime between 2004 and 2009.

4. The Oberon LGA had three legal practices in 1988-1990, two in 1991-93, and then a single legal practice until 2003. That practice seems to have then closed, as no legal practice is recorded for 2004.

5. Throughout the period 1988-2003 there was a single legal practice in the Wakool LGA, but no legal practice is recorded for 2004.

\section{CONCLUSION}

The further research questions thrown up by the legal practice data can be informed by the many ways in which the 'rural access to law' issue can be framed. At the highest level, the questions are quite simple. Of the lawyers who have left, merged, sold or closed up their practices - especially when doing so has left an area with no legal practice - one could ask 'Why?': 'What changed - in you, the region, the practice, the legal need, the demand?' Of the lawyers who have arrived in the area or expanded their practice one could ask similar questions to get at the reason 'why'. And of those who have stuck it out, one could ask simply 'How?': 'What do you do that makes a legal practice viable?'. Implicit in these simple, high level questions are a myriad of detailed questions ${ }^{121}$ that can uncover motivations, desires and needs that explain the presence, or not, of lawyers in rural Australia.

Differently from these types of questions are the 'What?' questions — those that are answered by data - and the possibilities for collecting and counting

${ }^{121}$ Such as those asked of a small sample by Hart, above n 39, 229-30 and Forell, Cain and Gray, above n 28, 33-4. 
are almost endless. While the legal practice data I collected offers some insights into where lawyers are going and where they are leaving, a much more finely cut analysis of the data, of both the legal practices and the population, is required before implications for access to justice become clear. Simply knowing where the lawyers are is not enough; the types of information that the Law and Justice Foundation asked for in a 2009 snapshot $^{122}$ need to be asked over a period of time, so that patterns emerge and idiosyncrasies are ironed out.

Overall, the evidence we need is evidence of both facts and feelings, in a way that acknowledges the many different ways that one can frame the simplystated issue of access to law in rural Australia.

${ }^{122}$ Forell, Cain and Gray, above n 28. 